\title{
Advanced Analytical and Bioanalytical Estimation of Ertugliflozin - An Overview
}

\section{Kranthi Yalla ${ }^{1 *}$, Dr. A Srinivasa Rao ${ }^{2}$, Madduluri Pavan Kumar ${ }^{3}$, Peram Bhargavi ${ }^{4}$}

1. Assistant professor, Department of Pharmaceutical Analysis, Shri Vishnu College of Pharmacy, Bhimavaram, Andhra Pradesh, India.

2. Professor and Head, Department of Pharmaceutical Analysis, Shri Vishnu College of Pharmacy, Bhimavaram, Andhra Pradesh, India.

3. Department of Pharmaceutical Analysis, Shri Vishnu College of Pharmacy, Bhimavaram, Andhra Pradesh, India.

4. Department of Pharmaceutical Analysis, Shri Vishnu College of Pharmacy, Bhimavaram, Andhra Pradesh, India.

*Corresponding author's E-mail: Kranthi.y@svcp.edu.in

Received: 02-09-2020; Revised: 16-11-2020; Accepted: 23-11-2020; Published on: 15-12-2020.

\section{ABSTRACT}

Ertugliflozin is a drug for the treatment of type 2 diabetes. It is used as a monotherapy and as a fixed dose combination with either sitagliptin or with metformin. Ertugliflozin is a sodium/glucose cotransporter 2 (SGLT2) inhibitor and is in the class of drugs known as gliflozins. The review describes different procedures for the analysis of Ertugliflozin as a single drug or in combinations available in the currently available literature in analytical and bioanalytical techniques. The analytical methods described here are explained in two parts Spectroscopy and Chromatography. Advance analytical techniques like 3D fluorescence Spectroscopy, HPLC, HILIC and UPLC MS/MS were used to estimate Ertugliflozin in pure, dosage forms and in rat plasma. This paper certainly helpful for the researchers engaged in method development and validation of Ertugliflozin.

Keywords: Ertugliflozin, UPLC MS/MS, HILIC, SGLT2 inhibitors, Analytical and bioanalytical techniques.

QUICK RESPONSE CODE $\rightarrow$

DOI:

10.47583/ijpsrr.2020.v65i02.005

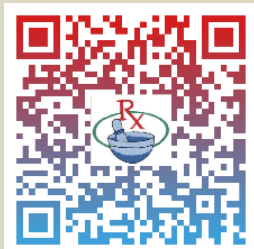

DOI link: http://dx.doi.org/10.47583/ijpsrr.2020.v65i02.005

\section{INTRODUCTION}

type rtug rtugliflozin is a drug used for the treatment for the type 2 diabetes. It is a sodium glucose co-transporter (SGLT2) inhibitor. SGLT2 inhibitors decrease renal glucose reabsorption and increase urinary glucose excretion, reducing fasting and postprandial blood glucose levels.

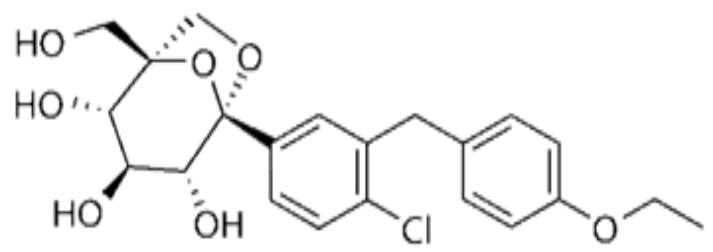

Figure 1: Showing structure of Ertugliflozin

IUPAC Name of ertugliflozin is (1S,2S,3S,4R,5S)-5-[4chloro-3-[(4-ethoxyphenyl) methyl] phenyl]-1(hydroxymethyl)-6,8-dioxabicyclo [3.2.1] octane-2,3,4triol

Molecular formula: $\mathrm{C}_{22} \mathrm{H}_{25} \mathrm{ClO}_{7}$

Molecular weight:436.9 Daltons. ${ }^{1}$
It is white in colour and powder in form soluble in ethanol and acetone, slightly soluble in ethyl acetate and acetonitrile and sparingly soluble in water. It is commercially available in single drug form and also combination with the Sitagliptin and metformin Hydrochloride. Collection of articles indicates the few bioanalytical, analytical method development and validation and stability indicating studies are available with the drug (ertugliflozin) and also with the combination of Sitagliptin and metformin. ${ }^{2}$

Ertugliflozin (trade name Steglatro) is a drug for the treatment of type 2 diabetes. In the United States, it was approved by the Food and Drug Administration for use as a monotherapy and as a fixed dose combination with either sitagliptin or with metformin. In Europe, it was approved in March 2018 for use as a monotherapy or combination therapy. Ertugliflozin is a sodium/glucose cotransporter 2 (SGLT2) inhibitor and is in the class of drugs known as gliflozins. A combination with metformin is marketed as Segluromet and a combination with sitagliptin is marketed as Steglujan.

\section{MATERIALS AND METHODS}

Author searched various online libraries available online related to determination of Hydroxychloroquine. The databases searched are, pubmed, wiley, science direct, taylor and francis, nature, BMJ and google scholar. The keywords used for search are 'determination of Ertugliflozin', 'estimation of Ertugliflozin', and 'Analytical and bioanalytical estimation of Ertugliflozin'. 


\section{Analytical methods}

China babu, et al., developed a stress indicating RP-HPLC method and validated for the simultaneous estimation of Ertugliflozin and Sitagliptin in Bulk and its formulation. The experiment was done in the Waters HPLC and separation took place in the c18 column capacitate $(250 \times 4.6 \mathrm{~mm}, 5$ $\mu \mathrm{m}$ particle size) (Waters), mobile phase was composed of $0.5 \mathrm{mM}$ of potassium dihydrogen orthophosphate (buffer) $\mathrm{Ph} 5.3$ and methanol $(55: 45) \mathrm{v} / \mathrm{v}$ peak elution of ertugliflozin at $2.3 \mathrm{~min}$ and Sitagliptin at $4.6 \mathrm{~min}$ they used the PDA (photo diode array detector) at $215 \mathrm{~nm}$ run time was $6 \mathrm{~min}$. LOD \& LOQ values was found to be $0.3 \mu \mathrm{g} / \mathrm{ml} \&$ $0.1 \mu \mathrm{g} / \mathrm{ml}$ for Ertugliflozin and Sitagliptin respectively.

They also develop a stress indicating studies in RP HPLC method mobile phase as $0.75 \mathrm{mM}$ di hydrogen orthophosphate buffer at $\mathrm{pH} 8.5$ and acetonitrile in the ratio of 60:40 v/v PDA detector was used and the detection was carried out at $263 \mathrm{~nm}$ with flow rate of $1.5 \mathrm{ml} / \mathrm{min}$. The validation parameters include system suitability, specificity, precision, linearity, accuracy, LOD\& LOQ and robustness. The linearity of ertugliflozin and Sitagliptin was found to be $0.9998 \& 0.9996$ respectively. The theoretical plates of ertugliflozin and Sitagliptin was found to be 3985\& 6425. The accuracy mean \%recovery of Ertugliflozin \&Sitagliptin was found to be 99.90 \& 100.91. The robustness of the method was performed by change of flow rate, temperature and mobile phase composition. ${ }^{3}$

Nizami et al., developed an analytical method and validated for simultaneous estimation of Ertugliflozin and Metformin in tablet dosage form by RP-HPLC method. The experiment was done on Waters HPLC and separation took place in the c18 column (150 mm x $4.6 \mathrm{mmd}, 5 \mu \mathrm{m})$ (Waters), mobile phase was composed of Potassium dihydrogen Ortho Phosphate: Acetonitrile (70:30v/v) and the flow rate of $1 \mathrm{ml} / \mathrm{min}$. PDA detector was used and the detection took place at $240 \mathrm{~nm}$. Retention time for ertugliflozin was at $3.2 \mathrm{~min}$ and for Metformin was at 2.1 min. In this method they validated parameters like linearity, accuracy, precision, selectivity, LOD\&LOQ etc. Theoretical plates for Ertugliflozin \& metformin is $4435 \&$ $4430^{4}$. The validation parameters according to ICH includes linearity over a range of $1.5-4.5 \mu \mathrm{g} / \mathrm{mL}$ and $100-300 \mu \mathrm{g} / \mathrm{ml}$ for ertugliflozin and metformin respectively. The percentage recovery obtained was found to be in the range of $99.889 \%$ - $99.631 \%$ for metformin and $100.181 \%$ $100.814 \%$ for Ertugliflozin. LOD \& LOQ values were found to be $0.43 \mu \mathrm{g} / \mathrm{ml} \& 1.30 \mu \mathrm{g} / \mathrm{ml}$ for Ertugliflozin and Metformin. ${ }^{4}$

Harshalatha P, et al., developed a novel RP-HPLC method for simultaneous determination of Ertugliflozin and Sitagliptin in bulk and tablet dosage forms the experiment was done in the Waters HPLC separation take place in $\mathrm{c} 18(250 \mathrm{~mm} \times 4.6 \mathrm{~mm} ; 5 \mu \mathrm{m})$ column by using the mobile phase composition of $0.2 \%$ orthophosphoricacid and acetonitrile (60:40) v/v. Flow rate was fixed at $1 \mathrm{~mL} / \mathrm{min}$ and the detection takes place with the photo diode array detector at $250 \mathrm{~nm}$ runtime is $6 \mathrm{~min}$ the peak elution of
Ertugliflozin and Sitagliptin is 2.3 and $3.9 \mathrm{~min}$. The validation parameters according to $\mathrm{ICH}$ includes selectivity, linearity, limit of detection, limit of quantification, robustness, precision, sensitivity \& accuracy. Theoretical Plate for Ertugliflozin\& Sitagliptin is $8496 \& 6482^{5}$. Linearity of ertugliflozin and Sitagliptin was obtained at a concentration of $32.50-97.50 \mu \mathrm{g} / \mathrm{ml}$ and $216.50-649.50$ $\mu \mathrm{g} / \mathrm{ml}$ respectively. Recovery study was carried out by analysing the samples at three different concentrations at 50,100 and $150 \%$. Robustness was assessed by changing in temp of column, flow rate, $\mathrm{pH}$ of mobile phase. ${ }^{5}$

Amtul Hadi Hadiya and Mohammad Yunoos developed a new validated stability indicating RP-HPLC method for the simultaneous estimation of Sitagliptin and ertugliflozin in bulk and tablet dosage forms. Chromatographic separation was carried out on Agilent ODS C18 (4.6 x 150 mm, $5 \mu$ particle size) column using a mobile phase composed of acetonitrile: phosphate buffer (adjusted to pH 5.4 with 0.1 $\%$ ortho phosphoric acid) in the ratio of $50: 50 \% \mathrm{v} / \mathrm{v}$ at a flow rate of $1.0 \mathrm{ml} / \mathrm{min}$. The analyte was monitored using UV detector wave length at $215 \mathrm{~nm}$ and the runtime is 10 min peak elution of ertugliflozin and Sitagliptin at 2.4 and 4.5 min respectively. The theoretical plates of Ertugliflozin was found to be 3493 sitagliptin was found to be 4706 . The method was validated according to $\mathrm{ICH}$ guidelines. Linearity range for Sitagliptin was $25-125 \mu \mathrm{g} / \mathrm{ml}$ and for Ertugliflozin was $3.75-22.5 \mu \mathrm{g} / \mathrm{ml}$. Using standard addition method at three different concentrations 50\%, 100\% and $150 \%$ the \% recovery of accuracy was demonstrated. Robustness was estimated at deliberate changes in flow rate, mobile organic phase, temperature. Stress studies were performed. ${ }^{6}$

P.V. Raoet al., developed a new stability indicating RPHPLC method for simultaneous estimation of ertugliflozin and Sitagliptin in bulk and pharmaceutical dosage forms. The experiment was carried out in HPLC (Waters) and separation took place in the Agilent column (150×4.6, $5 \mu \mathrm{m})$ dimensions. The mobile phase consists of buffer (Potassium di hydrogen Ortho Phosphate): Acetonitrile $(70: 30 \mathrm{~V} / \mathrm{V})$. The flow rate was maintained at $1.0 \mathrm{ml} / \mathrm{min}$. Retention time was $3.2 \mathrm{~min}$ (Ertugliflozin), $2.106 \mathrm{~min}$ (Sitagliptin) Photo Diode Array detector effluent monitored at $240 \mathrm{~nm}$. Acetonitrile and Water taken in the ratio of 50:50 used as a diluent. The method was validated according to $\mathrm{ICH}$ guidelines, linearity of Ertugliflozin and Sitagliptin was found in the range of $3.75-22.5 \mu \mathrm{g} / \mathrm{ml}$ and $25-0.150 \mu \mathrm{g} / \mathrm{ml}$ respectively. The mean recovery of Ertugliflozin and Sitagliptin were calculated and accepted with $100 \pm 2 \%$. Robustness includes the changes inflow rate, column temperature, mobile phase composition (Acetonitrile proportion). Degradation studies were conducted. $^{7}$

Venkateswara Rao et al., developed and validated a new stability indicating reverse phase HPLC method for simultaneously determination of metformin hydro chloride and ertugliflozin bulk and pharmaceutical dosage form. The experiment was done in Waters HPLC and 
separation take place in column BDSc8 $(150 \mathrm{~mm} \times 4.6 \mathrm{~mm} \times 5 \mathrm{~mm})$ and mobile phase was composed of buffer: acetonitrile $(55: 45 \mathrm{v} / \mathrm{v})$. The flow rate was maintained at $10 \mathrm{ml} / \mathrm{min}$ and detection was carried out by using photo diode array (PDA). Retention time for metformin was $2.33 \mathrm{ml} / \mathrm{min}$ and for Ertugliflozin was 3.136 $\mathrm{ml} / \mathrm{min}$. the validation parameters for this experiment was system suitability, linearity, precision, accuracy, robustness, LOD and LOD. The linearity values for metformin and Ertugliflozin was $125-170 \mathrm{mg} / \mathrm{ml}$ and $1.875-$ $11.25 \mathrm{mg} / \mathrm{ml}$. LOD and LOD was $1.70 \mathrm{mg} / \mathrm{ml}-5.16 \mathrm{mg} / \mathrm{ml}$ for metformin and Ertugliflozin was $0.07 \mathrm{mg} / \mathrm{ml}-0.21 \mathrm{mg} / \mathrm{ml}$. Accuracy value for metformin was $99.13 \%-101.63 \%$ and Ertugliflozin was 99.05\%- $101.10 \%$. Robustness was estimated by changing oven temperature $\left( \pm 5^{\circ} \mathrm{c}\right)$ mobile phase composition and flow rate was $( \pm 0.1 \mathrm{ml} / \mathrm{min}){ }^{8}$

Xiangjun Qiu et al., developed a UPLC MS/MS method for the quantification of ertugliflozin and Sitagliptin in rat plasma. The experiment was done in the UPLC MS/MS and separation takes place in the $\mathrm{BEH}$ c18 column $(2.1 \mathrm{~mm} \times 50 \mathrm{~mm} \times 1.7 \mathrm{~mm})$, mobile phase was composed of acetonitrile and water with $0.1 \%$ formic acid by gradient elution. Ertugliflozin was detected by $\mathrm{m} / \mathrm{z}$ 437.2- 329.0 transition for quantification and the $\mathrm{m} / \mathrm{z}$ 437.2- 207.5 transition for qualification, and Sitagliptin was monitored by $\mathrm{m} / \mathrm{z}$ 408.2-235.0 transition for quantification and $\mathrm{m} / \mathrm{z}$ 408.2-174.0 transition for qualification by multiple reaction monitoring (MRM) in positive electrospray ionization. The concentration of ertugliflozin was ranged from 1 to $1000 \mathrm{mg} / \mathrm{ml}$ and Sitagliptin was ranged from 2 to $2500 \mathrm{mg} / \mathrm{ml}$ the method exhibits good linearity. For both drugs intraday and inter day precision values was 1.6 $10.9 \%$ and $0.8-13.3 \%$.and accuracy values from $15.7-$ $14.6 \%$. The run time set as $3 \mathrm{~min}$ and flow rate was 0.4 $\mathrm{ml} / \mathrm{min}$. Quantification was achieved by multiple reaction monitoring (MRM) mode with transitions of $\mathrm{m} / \mathrm{z}$ $437.2 \rightarrow 329.0$ and $\mathrm{m} / \mathrm{z} 437.2 \rightarrow 207.5$ for ertugliflozin, $\mathrm{m} / \mathrm{z}$ $408.2 \rightarrow 235.0$ and $\mathrm{m} / \mathrm{z} 408.2 \rightarrow 174.0$ for sitagliptin and $\mathrm{m} / \mathrm{z}$ $285.0 \rightarrow 154.0$ for IS, respectively. Data acquisition and control of instrument were done by Masslynx 4.1 software. ${ }^{9}$

Yali Liang et al., studied effect of food on the pharmacokinetics of Ertugliflozin and its fixed dosage combinations (Ertugliflozin /Sitagliptin and Ertugliflozin/ metformin) was done in the Waters atlantis HILIC and separation take place in the column $(3 \mathrm{~mm} \times 2.1 \times 50 \mathrm{~mm})$ mobile phase was composed of acetonitrile: water $(80: 20 \mathrm{v} / \mathrm{v})$ containing $10 \mathrm{ml}$ ammonium acetate ( $\mathrm{pH} 4.7)$ and detection was performed by sciex API4000 in the positive ion mode and MRM values for Sitagliptin was $\mathrm{m} / \mathrm{z}$ 408-235 and metformin for 130-71 and plasma concentrations was determined based on the pharmacokinetics parameters like AUC, $C_{\max }, T_{\max }$. The $\mathrm{T}_{\max }$ value for metformin was 2.3 hours(fasted) 4.0hours(fed) and Sitagliptin was 3.0hours(fasted), 1.8 hours(fed). AUC was within the bioequivalence range $80 \%-125 \%$ for Ertugliflozin and $\mathrm{C}_{\max }$ value for metformin decreased to $29 \%$ in fed state and Sitagliptin was $90 \% .{ }^{10}$
M.Anjali, et al., developed and validated an UV method on Ertugliflozin and Sitagliptin by Using Simultaneous Equation Method. The experiment was done in the UV spectrophotometer (PG instruments) This Method solving of simultaneous equations based on the measurement of absorbance at two wavelengths, $210 \mathrm{~nm}$ and $221 \mathrm{~nm}$. Mixture of HPLC grade water and Acetonitrile taken in the ratio $1: 1 \mathrm{v} / \mathrm{v}$ used as diluent and sonicated for $15 \mathrm{~min}$ Working solutions of both drugs were scanned in the UV range $200-400 \mathrm{~nm}$. The overlay spectra of both drugs were recorded. The wavelengths $210 \mathrm{~nm}$ (of STG) and $221 \mathrm{~nm}$ (of ETR) were selected for analysis of both drugs using simultaneous equation method $(210 \mathrm{~nm}$ for Sitagliptin and $221 \mathrm{~nm}$ for Ertugliflozin). The method was validated according to $\mathrm{ICH}$ guidelines. Specificity, precision and ruggedness was estimated and\% RSD was found to be less than $2 \%$. Robustness of the method was evaluated by changing the wavelength by $\pm 2 \mathrm{~nm}$. \% RSD obtained was less than $2 \%{ }^{11}$

Wenjing wang et al., study on the interaction of ertugliflozin in human serum albumin invitro by multiple spectroscopic methods and molecular docking and molecular dynamics simulation. The experiment was performed using multiple spectroscopic methods, they are as follows:

a. Fluorescence spectroscopy: Excitation wavelength $280 \mathrm{~nm}$ and emission spectra was measured at 290$500 \mathrm{~nm}$ at the temperatures of 298,304 and $310 \mathrm{k}$. HSA solution diluted to $2 \mu \mathrm{m}$ and ertugliflozin final concentrations from 0 to $140 \mu \mathrm{m}$.

b. Fluorescence lifetime: Excited wavelength $280 \mathrm{~nm}$ emission wavelength $337 \mathrm{~nm}$. HSA concentration was $2 \mu \mathrm{m}$ and ertugliflozin was 80 and $140 \mu \mathrm{m}$.

c. 3D fluorescence spectroscopy: Excitation and emission wavelength of HSA was found to be 280, 335 $\mathrm{nm}$ and 225,334nm for peak 1 and peak 2 respectively. Excitation and emission wavelength of ErtugliflozinHSA (30:1) was found to be $280,329 \mathrm{~nm}$ and $225,322 \mathrm{~nm}$ for peak 1 and peak 2 respectively. ${ }^{12}$

Laxmi, et al., developed a RP-HPLC method for simultaneous estimation of Ertugliflozin and Sitagliptin in bulk and tablet dosage forms. The experiment was done in the waters HPLC and separation takes place in the $\mathrm{C} 18$ column $(250 \mathrm{~mm} \times 4.6 \mathrm{~mm}$ I.D., $5 \mu \mathrm{m})$, mobile phase used for separation is $0.1 \mathrm{M}$ dipotassium hydrogen phosphate and methanol (65:35)v/v. Peak elution of ertugliflozin was at $3.02 \mathrm{~min}$ and run time is $7 \mathrm{~min}$ and detected by PDA detector at $225 \mathrm{~nm}$ wavelength, flow rate is $1 \mathrm{ml} / \mathrm{min}$ and $\mathrm{pH}$ is adjusted to 3.5. The method was validated according to $\mathrm{ICH}$ guidelines. The relationship was found to be linear in the range $50-150 \mu \mathrm{g} / \mathrm{ml}$ for Sitagliptin and 7.5 $22.50 \mu \mathrm{g} / \mathrm{ml}$ for ertugliflozin. The robustness of method was tested by assessing the effect of minor changes in the Flow rate of mobile phase $( \pm 0.1 \mathrm{ml} / \mathrm{min}) \mathrm{pH}$, detection $\lambda$, mobile phase ratio, Column temperature $\left( \pm 2^{\circ} \mathrm{C}\right)$. The LOD \& LOQ was found to be 0.071 and $0.237 \mu \mathrm{g} / \mathrm{ml}^{13}$ 
D.G. Han, et al., developed a HPLC method combined with fluorescence detection for determination of ertugliflozin in rat plasma. They described a novel bioanalytical method using high-performance liquid chromatography (HPLC) coupled with fluorescence detection. separation was performed on a Kinetex C18 column $(250 \times 4.6 \mathrm{~mm}, 5 \mu \mathrm{m}$, $100 \AA$; Phenomenex, Torrance, CA, USA) protected by a C18 guard column with an isocratic mobile phase comprising acetonitrile and $10 \mathrm{mM}$ potassium phosphate buffer ( $\mathrm{pH}$ 6.0). The flow rate of $1 \mathrm{~mL} / \mathrm{min}$. Injection volume was $20 \mu \mathrm{L}$ and total run time was $20 \mathrm{~min}$. The peak was detected by a fluorescence detector at an optimized excitation \& emission wavelength pair of $277 \& 320 \mathrm{~nm}$ respectively. The method was validated according to $\mathrm{ICH}$ guidelines. Calibration curves $(n=5)$ were constructed by plotting the peak area ratios of ERTU to IS (y-axis) versus the concentration ratios of ERTU $(4-2000 \mathrm{ng} / \mathrm{mL})$ to IS $(1000 \mathrm{ng} / \mathrm{mL})$ in plasma (x-axis) using linear regression analysis. ${ }^{14}$

A Lakshmana Rao\& U Krishnaveni, developed a stability indicating RP-HPLC method for simultaneous estimation of metformin and ertugliflozin. The analysis of drugs was carried out on Waters HPLC 2695Isocratic separation was achieved on Denali C18 $(150 \times 4.6 \mathrm{~mm}, 5 \mu \mathrm{m})$ column with mobile phase comprising of $0.01 \mathrm{~N} \mathrm{KH}_{2} \mathrm{PO}_{4}$ : acetonitrile (60:40 V/V), pH adjusted to 5.4 with $0.01 \%$ ortho phosphoric acid. The flow rate was maintained at $1 \mathrm{~mL} / \mathrm{min}$ and analytes were detected with UV detector at $224 \mathrm{~nm}$ and run time kept was 6 min. peak elution of Ertugliflozin and metformin is $3.20 \mathrm{~min}$ and $2.35 \mathrm{~min}$ respectively. The sample injector volume was $20 \mu \mathrm{L}$ with analysis being carried out at ambient temperature. The method was validated according to $\mathrm{ICH}$ guidelines. Theoretical plates for metformin and ertugliflozin were 5675\& 7593. Linearity concentrations of Metformin was $62.5-375 \mu \mathrm{g} / \mathrm{mL}$ and Ertugliflozin was $0.9375-5.625 \mu \mathrm{g} / \mathrm{mL}$. The mean percentage recovery at each level was not less than $98 \%$ and not more than $102 \%$. Robustness was evaluated by changing in flow rate, mobile phase composition and temperature. ${ }^{15}$

Syed Wajahat Shafaat, et al., developed the analytical method development and validation for simultaneous estimation of ertugliflozin and metformin $\mathrm{HCl}$ in bulk and pharmaceutical dosage form by HPLC experiment done in $\mathrm{HPLC}$ in gradient type \&the column is C18 $(250 \times 4.6 \mathrm{~mm})$ mobile phase was composition of Potassium dihydrogen phosphate buffer and methanol (65:35) v/v and the flow rate was maintained at $1.0 \mathrm{~mL} / \mathrm{min}$. Detection took place in UV detector at the wave length of $220 \mathrm{~nm}$ and the run time is $6 \mathrm{~min}$.Peak elution of Ertugliflozin and metformin $\mathrm{HCl}$ is at $3.2 \mathrm{~min}$ and $2.1 \mathrm{~min}^{16}$

The following table gives details about discussed Chromatographic methods:

\begin{tabular}{|c|c|c|c|c|c|c|c|c|c|}
\hline Authors & Method & Column & Mobile phase & $\begin{array}{c}\text { Flow } \\
\text { Rate } \\
\text { (ml/min) }\end{array}$ & $\begin{array}{c}\text { Detection } \\
\text { wavelength }\end{array}$ & $\underset{(\mathrm{min})}{\mathbf{R t}}$ & $\begin{array}{l}\text { LOD } \\
(\mu \mathrm{g} / \\
\mathrm{ml})\end{array}$ & $\begin{array}{c}\text { LOQ } \\
(\mu \mathrm{g} / \mathrm{ml})\end{array}$ & Ref \\
\hline $\begin{array}{l}\text { China babu, } \\
\text { et al., }\end{array}$ & RP-HPLC & $\begin{array}{c}\text { C18 } \\
\text { capacitate }\end{array}$ & $\begin{array}{c}\text { 0.5mM potassium } \\
\text { dihydrogen phosphate } \\
\text { (buffer of } \mathrm{pH} 5.3 \text { ): } \\
\text { methanol }(55: 45) \mathrm{v} / \mathrm{v}\end{array}$ & 1 & $\begin{array}{l}\text { PDA with } \\
215 \mathrm{~nm}\end{array}$ & 2.3 & 0.3 & 0.11 & 3 \\
\hline Nizami, et al., & RP-HPLC & $\mathrm{C} 18$ & $\begin{array}{l}\text { Potassium dihydrogen } \\
\text { ortho phosphate: } \\
\text { Acetonitrile }(70: 30) \mathrm{v} / \mathrm{v}\end{array}$ & 1 & $\begin{array}{l}\text { PDA with } \\
240 \mathrm{~nm}\end{array}$ & 3.2 & 0.43 & 1.30 & 4 \\
\hline $\begin{array}{l}\text { Harshalatha } \\
\text { P, et al., }\end{array}$ & RP-HPLC & $\mathrm{C} 18$ & $\begin{array}{c}0.2 \% \text { ortho phosphoric } \\
\text { acid: Acetonitrile (60:40) } \\
\mathrm{v} / \mathrm{v}\end{array}$ & 1 & $\begin{array}{l}\text { UV with } \\
250 \mathrm{~nm}\end{array}$ & 2.3 & 0.0068 & 0.029 & 5 \\
\hline $\begin{array}{l}\text { Amtul Hadi } \\
\text { Hadiya and } \\
\text { Yunoos }\end{array}$ & RP-HPLC & ODS C8 & $\begin{array}{c}\text { Acetonitrile: phosphate } \\
\text { buffer (pH } 5.4 \text { with } 0.1 \% \\
\text { ortho phosphoric acid) } \\
(50: 50) \mathrm{v} / \mathrm{v}\end{array}$ & 1 & $\begin{array}{l}\text { UV with } \\
215 \mathrm{~nm}\end{array}$ & 2.4 & 0.08 & 0.244 & 6 \\
\hline $\begin{array}{l}\text { P. V. Rao et } \\
\text { al., }\end{array}$ & RP-HPLC & $\begin{array}{l}\text { Agilent } \\
\text { column }\end{array}$ & $\begin{array}{l}\text { Potassium dihydrogen } \\
\text { ortho phosphate (buffer): } \\
\text { Acetonitrile (70:30) v/v }\end{array}$ & 1 & $\begin{array}{l}\text { PDA with } \\
240 \mathrm{~nm}\end{array}$ & 3.2 & 0.43 & 1.31 & 7 \\
\hline $\begin{array}{l}\text { Venkateswara } \\
\text { Rao et al., }\end{array}$ & RP-HPLC & BDS C8 & $\begin{array}{l}\text { Potassium dihydrogen } \\
\text { ortho phosphate (buffer): } \\
\text { acetonitrile (55:45) v/v }\end{array}$ & 1 & $\begin{array}{l}\text { PDA with } \\
224 \mathrm{~nm}\end{array}$ & 3.13 & 0.07 & 0.21 & 8 \\
\hline $\begin{array}{l}\text { Xiangjun } \\
\text { Qiuet al., }\end{array}$ & $\begin{array}{l}\text { UHPLC- } \\
\text { MS/MS }\end{array}$ & BEH C18 & $\begin{array}{c}\text { Gradient elution } \\
\text { Acetonitrile }(\mathrm{A}) \text { and } \\
\text { water with } 0.1 \% \text { formic } \\
\text { acid (B) }\end{array}$ & 0.4 & $\begin{array}{c}\text { MS with } \\
\text { triple } \\
\text { quadrupole } \\
\text { and } \mathrm{m} / \mathrm{z} \text { of } \\
437.2>329.0 \\
432.7>20\end{array}$ & 1.44 & - & $1 \mathrm{ng} / \mathrm{ml}$ & 9 \\
\hline
\end{tabular}




\begin{tabular}{|c|c|c|c|c|c|c|c|c|c|}
\hline Laxmi, et al., & RP-HPLC & $\mathrm{C} 18$ & $\begin{array}{l}0.1 \mathrm{M} \text { dipotassium } \\
\text { hydrogen phosphate: } \\
\text { methanol }(65: 35) \mathrm{v} / \mathrm{v}\end{array}$ & 1 & $\begin{array}{l}\text { PDA with } \\
225 \mathrm{~nm}\end{array}$ & 3.028 & 0.071 & 0.237 & 13 \\
\hline $\begin{array}{l}\text { D.G. Han, et } \\
\text { al., }\end{array}$ & RP-HPLC & $\mathrm{C} 18$ & $\begin{array}{l}\text { Acetonitrile and } 10 \mathrm{mM} \\
\text { potassium phosphate } \\
\text { buffer }(\mathrm{pH} \mathrm{6)}(65: 35) \mathrm{v} / \mathrm{v}\end{array}$ & 1 & $\begin{array}{c}\text { Fluorescence } \\
\text { with } \\
\text { excitation } \\
\text { wavelength - } \\
277 \mathrm{~nm} \\
\text { Emission } \\
\text { wavelength - } \\
320 \mathrm{~nm}\end{array}$ & 11.1 & - & $4 \mathrm{ng} / \mathrm{ml}$ & 14 \\
\hline $\begin{array}{l}\text { A Lakshmana } \\
\text { Rao \& U } \\
\text { Krishnaveni }\end{array}$ & RP-HPLC & $\begin{array}{l}\text { Denali } \\
\text { C18 }\end{array}$ & $\begin{array}{c}0.01 \mathrm{~N} \mathrm{KH}_{2} \mathrm{PO}_{4}: \\
\text { acetonitrile }(60: 40) \mathrm{v} / \mathrm{v} \\
\text { pH adjusted to } 5.4\end{array}$ & 1 & $\begin{array}{l}\text { UV with } \\
224 \mathrm{~nm}\end{array}$ & 3.2 & 0.72 & 0.04 & 15 \\
\hline $\begin{array}{l}\text { Syed Wajahat } \\
\text { Shafaat, et } \\
\text { al., }\end{array}$ & HPLC & $\begin{array}{l}\text { Inertsil } \\
\text { C18 }\end{array}$ & $\begin{array}{c}\text { Buffer: methanol }(65: 35) \\
\text { v/v pH:4.0 }\end{array}$ & 1 & $220 \mathrm{~nm}$ & 7.35 & 9.61 & 0.006 & 16 \\
\hline
\end{tabular}

Tabulation Showing Spectrophotometric data of Ertugliflozin

\begin{tabular}{|c|c|c|c|}
\hline Parameters & Sitagliptin & Ertugliflozin & LIMIT \\
\hline $\begin{array}{l}\text { Linearity } \\
(\mu \mathrm{g} / \mathrm{ml})\end{array}$ & $7-42 \mu \mathrm{g} / \mathrm{ml}$ & $\begin{array}{l}1.05-6.30 \\
\mu \mathrm{g} / \mathrm{ml}\end{array}$ & $\mathrm{R}<1$ \\
\hline \multicolumn{4}{|l|}{ Solvent } \\
\hline LOD & 0.07 & 0.0105 & NMT 3 \\
\hline LOQ & 0.21 & 0.0315 & NMT 10 \\
\hline Wavelength $\left(\lambda_{\max }\right)$ & $210 \mathrm{~nm}$ & $221 \mathrm{~nm}$ & --- \\
\hline Reference & & 11 & \\
\hline
\end{tabular}

\section{CONCLUSION}

Most of the methods discussed used HPLC with UV detection for estimation of Ertugliflozin. HPLC and LC MS/MS were used for the estimation of drug in biological fluids. One method discussed about interaction of ertugliflozin in human serum albumin invitro by multiple spectroscopic methods like Fluorescence spectroscopy, Fluorescence life time and 3D fluorescence spectroscopy. Pharmacokinetic study of Ertugliflozin and its fixed dosage combinations by using HPLC and LC MS/MS was discussed. Different spectrophotometry and chromatographic methods were presented here in a systematic way and easy understandable language.

\section{REFERENCES}

1. Ertugliflozin - DrugBank [Internet]. [cited 2020 Aug 15]. Available from: https://www.drugbank.ca/drugs/DB11827

2. Cinti F, Moffa S, Impronta F, Cefalo CMA, Sun VA, Sorice G, et al. Spotlight on ertugliflozin and its potential in the treatment of type 2 diabetes: Evidence to date. Vol. 11, Drug Design, Development and Therapy. Dove Medical Press Ltd.; 2017. p. 2905-19.

3. China Babu D, Madhusudhana Chetty C, Mastanamma S." A new stress indicating RP-HPLC method development and validation for the simultaneous estimation of ertugliflozin and metformin in bulk and its tablet dosage form.",'oriental journal of chemistry'. Indian Drugs. 56(2), 2019, 39-46.

4. Tahir Nizami BS and PS." Analytical method development and validation for simultaneous estimation ofertuglifozin and metformin in tablet dosage form by RP-HPLC".'international jounal of pharmacy and life science'. J Glob Pharma Technol. 10(10), 2018, 6-14.

5. Harshalatha P KBC and CM. "a novel RP-HPLC method for simeltenious estimation ofertuglifozin and sitagliptin in bulk and tablet doasage form".' INTERNATIONAL JOURNAL OF RESEARCH IN PHARMACEUTICAL SCIENCES'. Int J Res Pharm Sci. 10(1), 2018, 339-45.

6. Amtul Hadi Hadiya and Mohammad Yunoos ."a new validated stability indicating rp-hplc method for the simultaneous estimation of sitagliptin and ertugliflozin in bulk drug and formulation". 'Indo American journal of pharmaceutical sciences', 05(09), 2018, 8785-94.

7. P.venkateswara rao, A lakshmana rao S prasad."simultaneous estimation of ertugliflozin and sitagliptin in bulk and pharmaceutical dosage form its validation parametrs as per ich guidelines",' Indo American journal of pharmaceutical sciences'. 05(04), 2018, 2616-27.

8. Rao P V, Rao A L, Svum P. "Development and Validation of New Stability Indicating Reversed-Phase High-Performance Liquid Chromatography Method for Simultaneous Determination of Metformin Hydrochloride and Ertugliflozin in Bulk and Pharmaceutical Dosage Form".' Asian J Pharm Clin Res'. 12(1), 2019, 235.

9. Qiu X, Xie S, Ye L, Xu R ai." UPLC-MS/MS method for the quantification of ertugliflozin and sitagliptin in rat plasma".' Anal Biochem '[Internet]. 567, 2019, 112-6.

10. Sahasrabudhe V, Fediuk DJ, Matschke K, Shi H, Liang $Y$, Hickman A, et al." Effect of Food on the Pharmacokinetics of Ertugliflozin and Its Fixed-Dose Combinations Ertugliflozin/Sitagliptin and Ertugliflozin/Metformin",'internationaql journal of pharmaceutical science and research' Clin Pharmacol Drug Dev. 8(5), 2019, 619-27.

11. Anjali M, Manaaz, Shreshta M, Prasanna R, Shrisha T, Kumar MS." Method Development and Validation of Ertugliflozin and Sitagliptin by Using Simultaneous Equation Method". 'J 
Innov Pharm Sci'. 3(1), 2019, 22-8.

12. Wang W, Gan N, Sun Q, Wu D, Gan R, Zhang M, et al." Study on the interaction of ertugliflozin with human serum albumin in vitro by multispectroscopic methods, molecular docking, and molecular dynamics simulation".' Spectrochim Acta - Part A Mol Biomol Spectrosc'. 219, 2019, 83-90.

13. M. Laxmi, S. Marakatham, R . V. Valli Kumari MSK." RP-HPLC Method Development And Validation For Simultaneous Estimation Of Ertugliflozin And Sitagliptin In Bulk And Tablet Dosage Forms". 'Indian J Appl Res' [Internet]. 9(10), 2019, 913.

14. Han DG, Yun H, In-Soo Yoon." A novel high-performance liquid chromatographic method combined with fluorescence detection for determination of ertugliflozin in rat plasma:
Assessment of pharmacokinetic drug interaction potential of ertugliflozin with mefenamic acid and ketoconazole'. 'J Chromatogr B Anal Technol Biomed Life Sci' [Internet]. 2019, 1122-1123(March), 49-57.

15. Rao AL, Krishnaveni U." Stability Indicating RP-HPLC Method for Simultaneous Estimation of Metformin and Ertugliflozin",'journal of pharmaceutical and medicinal chemistry'. 5(2), 2019, 1-9.

16. Syed Wajahat Shafaat, Aejaz Ahmed, G. J. Khan SA and AAQ. "analytical method development and validation for simultaneous estimation of ertugliflozin and metformin hcl in bulk and pharmaceutical dosage formby ",'J Chem Inf Model'. 53(9), 2019, 1689-99.

Source of Support: None declared.

Conflict of Interest: None declared.

For any question relates to this article, please reach us at: editor@globalresearchonline.net

New manuscripts for publication can be submitted at: submit@globalresearchonline.net and submit_ijpsrr@rediffmail.com 